\title{
Budesonide/formoterol maintenance and reliever therapy in primary care asthma management: effects on bronchial hyperresponsiveness and asthma control
}

\author{
*Roland A Riemersma ${ }^{a, b}$, Dirkje Postma ${ }^{a, b}$, Thys van der Molen \\ a Department of General Practice, University Medical Center Groningen, Groningen, The Netherlands \\ ${ }^{b}$ Department of Pulmonary Medicine and Tuberculosis, University Medical Center Groningen, Groningen, The Netherlands
}

Received 17th July 2011; revised 8th September 2011; accepted 9th September 2011; online 21st October 2011

\begin{abstract}
Background: The management of asthma has changed since the introduction of budesonide/formoterol (Symbicort ${ }^{\circledast}$ ) as both maintenance and reliever therapy (SMART). SMART and its effects on bronchial hyperresponsiveness (BHR) have not been studied in primary care.

Aims: To compare the effects of SMART and guideline-driven usual care (UC) on BHR and clinical asthma severity in primary care practice. Methods: Patients with mild-to-moderate stable asthma were randomised to receive SMART treatment ( $n=54$ ) (budesonide/formoterol $80 / 4.5 \mu \mathrm{g}$ Turbuhaler ${ }^{\circledast}$, two puffs once daily and extra inhalations as needed) or UC treatment ( $\mathrm{n}=48$ ) for 12 months. Diary data, Asthma Control Questionnaire scores, forced expiratory volume in 1 second ( $F E V_{1}$ ), and peak expiratory flow (PEF) measurements were collected during run-in and after $1,3,6$, and 12 months of treatment. BHR, measured as the dose of histamine provoking a fall in $\mathrm{FEV} \mathrm{V}_{1}$ of $20 \%$ ( $\mathrm{PD}_{20}$-histamine), was determined at randomisation and after 12 months.

Results: One hundred and two patients with asthma participated in the study. The change in PD20-histamine during the study was not significantly different between the SMART and UC groups $(p=0.26)$. The mean inhaled corticosteroid (ICS) dose was $326 \mu \mathrm{g}$ beclomethasone dipropionate (BDP) equivalents/day (95\% CI 254 to 399) with SMART, which was significantly lower ( $p<0.0001)$ than the mean ICS dose with UC treatment $(798 \mu \mathrm{g}$ BDP equivalents/day (95\% CI 721 to 875). Morning and evening PEF values increased significantly with SMART treatment compared with UC; FEV 1 , symptoms and asthma control did not differ.

Conclusions: Despite a 59\% lower dose of ICS, BHR and other clinical outcomes remained stable during SMART treatment while PEF values improved.

(C) 2012 Primary Care Respiratory Society UK. All rights reserved.

R Riemersma et al. Prim Care Respir J 2012; 21(1): 50-56

http://dx.doi.org/10.4104/pcrj.2011.00090
\end{abstract}

Keywords asthma, management, primary care, randomised controlled trial, SMART, bronchial hyperresponsiveness

\section{See linked editorial by Thomas \& Pavord on pg 8}

The full version of this paper, with online appendix is available online at www.thepcrj.org

\section{Introduction}

Asthma is a chronic inflammatory disorder of the airways associated with airway hyperresponsiveness that leads to recurrent respiratory symptoms. ' Long-term anti-inflammatory treatment with inhaled corticosteroids (ICS) is the cornerstone of therapy in persistent asthma. It reduces asthma symptoms and numbers of exacerbations, improves lung function, and is accompanied by a reduction in airway inflammation. ${ }^{1-3}$ Several studies have shown that adding a long-acting $\beta_{2}$-agonist (LABA) to ICS may be beneficial in asthma management. This has led to the development of fixed combination inhalers of ICS and LABA. ${ }^{47}$

A recent development in the management of asthma is the use of the combination inhaler budesonide/formoterol (Symbicort ${ }^{\oplus}$ ) both as Maintenance And as Reliever Therapy (SMART) (Symbicort ${ }^{\circledR}$ SMART $^{\oplus}$, AstraZeneca, Sweden). This approach is possible because formoterol provides rapid symptom

\footnotetext{
* Corresponding author: Dr Roland A Riemersma, University Medical Center Groningen - General Practice, P O Box 196, Groningen 9700 AD, The Netherlands. Tel: +31596622183 Fax: +31596683455 E-mail: ra.riemersma@home.nl
} 
relief, making use of a separate short acting $\beta_{2}$-agonist redundant. ${ }^{8-11}$ When taking an extra puff for symptom relief, an additional dose of ICS and formoterol is administered simultaneously, thereby preventing a deterioration or even an exacerbation. ${ }^{12}$ Studies testing the SMART concept have shown beneficial effects on the time to first asthma exacerbation, exacerbation rate, and number of days with asthma control compared with other treatment regimens. Importantly, this approach reduces the ICS dose needed to remain in a stable state of disease. ${ }^{13-18}$

The effects of the SMART concept on bronchial hyperresponsiveness (BHR) - a hallmark of asthma - have not yet been investigated, nor has it been studied in primary care. This is of importance since primary care physicians manage the largest proportion of patients with asthma (up to $75 \%$ ). These patients generally have much milder disease than patients treated in secondary care. ${ }^{19}$

This study compares the effects of budesonide/formoterol SMART on BHR with usual care (UC) treatment based on Global Initiative for Asthma (GINA) guidelines in patients with mild-tomoderate asthma in primary care. ' We anticipated that BHR with SMART would be better than with UC, or equal to UC but with a lower dose of ICS with SMART. Secondary outcomes were asthma control, exacerbations, symptoms and lung function, Asthma Control Questionnaire (ACQ-5), Satisfaction with Asthma Treatment Questionnaire (SATQ), and mean dose of ICS used..$^{20-22}$

\section{Methods}

\section{Ethical approval}

The study was approved by the Medical Ethics Committee of the University Medical Center Groningen, The Netherlands (METC 2003/111). All patients provided written informed consent. The study was conducted in accordance with the Declaration of Helsinki and Good Clinical Practice guidelines

\section{Patients}

Patients with mild-to-moderate persistent asthma of either sex aged $\geq 18$ years were selected from 32 general practices. The complete list of exclusion, enrolment and randomisation criteria are presented in Appendix 1 (available online at www.thepcrj.org). After the run-in period (Figure 1), patients were stratified according to the daily dose of ICS $(<800 \mu \mathrm{g}$ vs. $\geq 800 \mu \mathrm{g}$ budesonide/beclomethasone dipropionate (BDP) or $<500 \mu \mathrm{g}$ vs. $\geq 500 \mu \mathrm{g}$ fluticasone propionate) and dose of histamine provoking a fall in forced expiratory volume in 1 second $\left(\mathrm{FEV}_{1}\right)$ of $20 \%$ ( $\mathrm{PD}_{20}$-histamine; $>1 \mathrm{mg}$ vs. $\leq 1 \mathrm{mg}$ ) to create balanced groups.

\section{Study design and flowchart}

The study was designed as an open, parallel-group, multicentre study conducted in two centres. After a 4-week run-in period, eligible patients were randomly assigned to treatment according to SMART or treatment based on GINA guidelines (UC group). ${ }^{1}$

Patients randomised to SMART treatment were instructed to
Figure 1. Study flow chart, $\mathrm{V}=$ visit, $\mathrm{T}=$ telephone contact

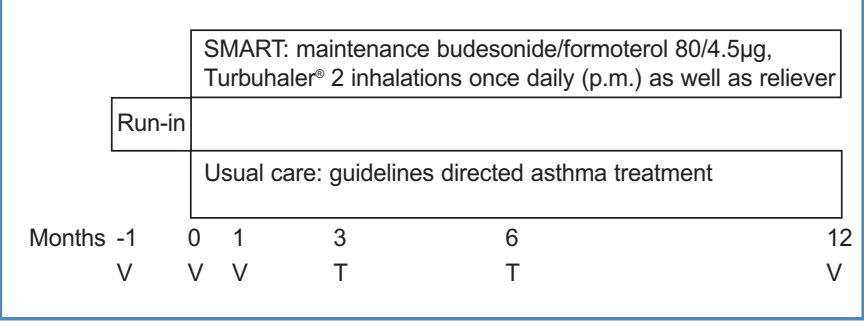

take two inhalations of the lowest available budesonide/formoterol dose of $80 / 4.5 \mu \mathrm{g}$ once daily in the evening and additional inhalations for symptom relief as replacement for a short-acting $\beta_{2}$-agonist. For safety reasons, patients were instructed to contact the investigator if $\geq 12$ inhalations were needed on two consecutive days. No other asthma medication was allowed.

Patients in the UC group continued medication as before randomisation. They were treated as usual by their general practitioner (GP). Patients in both groups were instructed to contact their GP in case of a (threatening) exacerbation. Their GP treated the exacerbation but was not allowed to change the maintenance treatment in the SMART group.

Figure 1 shows the flowchart of the study. No scheduled contacts took place during the last 6 months of the study. We therefore kept contacts between investigators and patients as limited as possible as a reflection of the 'real-life' character of the study.

\section{Data collection and procedures}

BHR measured by $\mathrm{PD}_{20}$-histamine was the primary outcome. Histamine provocation, lung function, and reversibility tests were performed according to European Respiratory Society (ERS) guidelines by the same lung function assistant. ${ }^{23}$

PD 20-histamine was assessed using the dosimeter method at randomisation and after 12 months of treatment. The second test was performed at the same time of the day (within 1 hour) as the baseline test and was postponed if the pre-challenge $\mathrm{FEV}_{1}$ was $<60 \%$ of predicted normal, $<1.5 \mathrm{~L}$, or differed by $>15 \%$ from baseline. The PD20-histamine was calculated from a loghistamine dose versus the percentage fall in $\mathrm{FEV}_{1}$ by linear interpolation. $\mathrm{PD}_{20}$-histamine is the calculated dose in $\mathrm{mg}$ at which an exact fall of $20 \%$ would have been observed. In case a fall of $20 \%$ was reached at inhalation of saline, $\mathrm{PD}_{20}$ was arbitrarily set at $0.005 \mathrm{mg}$. In case a fall of $20 \%$ was reached at the lowest dose $(0.02 \mathrm{mg}), \mathrm{PD}_{20}$ was arbitrarily set at $0.01 \mathrm{mg}$. Since $\mathrm{PD}_{20}$ data are not normally distributed, they were transformed logarithmically with 2 as base. The differences or changes were expressed as 'doubling dose steps' where a difference of 1 means a doubling or halving of the $\mathrm{PD}_{20}$ value. $\mathrm{FEV}_{1}$ and forced vital capacity (FVC) measures were performed at randomisation and after 1 and 12 months of treatment. Reversibility was tested at the start of the run-in period using two inhalations of $0.5 \mathrm{mg}$ terbutaline (Bricany ${ }^{\circledR}$, Turbuhaler ${ }^{\circledast}$, 
AstraZeneca, Sweden).

Secondary outcomes were calculated from daily diary card data during run-in and 4 weeks prior to each clinic visit or telephone contact and from two questionnaires: the Asthma Control Questionnaire (ACQ-5, 20,21 all clinic visits) and the Satisfaction with Asthma Treatment Questionnaire (SATQ, after 1 and 12 months of treatment). ${ }^{22}$

Patients recorded daily the best of three morning and evening peak expiratory flow (PEF) values, asthma symptoms during night and day (3-point scale where $0=$ no symptoms and $3=$ =incapacitating symptoms), nights with awakenings due to asthma symptoms, total number of budesonide/formoterol inhalations (SMART group), and intake of maintenance and asneeded medication (UC group). Diary card data were also used to calculate the number of mild asthma exacerbation days (a day with either a morning PEF $<80 \%$ of the run-in average value or a night with awakenings due to asthma symptoms), the number of asthma control days (a night and day with no asthma symptoms and a night with no awakenings due to asthma symptoms), the number of severe asthma exacerbations (deterioration in asthma resulting in hospitalisation or emergency room treatment or need for oral glucocorticosteroid treatment for at least 3 days), and the time to first severe asthma exacerbation.

Safety was investigated by assessing the nature, incidence, and severity of adverse events.

\section{Statistical analysis}

Efficacy analysis was carried out on all randomised patients. All tests performed were two-sided and a $p$ value $\leq 0.05$ was considered statistically significant. If necessary, 'last observation carried forward' was used to impute missing values for ACQ and SATQ scores at 12 months of treatment if a value existed after 6 months of treatment. The change in $\mathrm{PD}_{20}$-histamine before and after 12 months of treatment was analysed by ANOVA using a multiplicative model (i.e. analysing log-transformed $\mathrm{PD}_{20}$ histamine with treatment as fixed factor and log-transformed $\mathrm{PD}_{20}$-histamine at baseline as covariate). The least-squared means resulting from this model were used to estimate the treatment difference in log PD20-histamine and to calculate two-sided 95\% confidence intervals $(\mathrm{Cl})$, which are presented as the anti-log.

Changes in $\mathrm{FEV}_{1}$ percentage predicted, overall ACQ scores, and in both the domain and total score of the SATQ after 12 months of treatment were analysed by ANOVA. The number of asthma control days was expressed as the percentage of the total number of days recorded in the diaries. Baseline values were calculated from diary recordings of the last 10 days of the run-in period.

The daily dose of ICS used was expressed in $\mu \mathrm{g} /$ day equivalents of beclomethasone dipropionate (BDP), taking an approximate equivalence of $1000 \mu \mathrm{g} /$ day $B D P=800 \mu \mathrm{g} / \mathrm{day}$ budesonide $=500 \mu \mathrm{g} /$ day fluticasone propionate. ${ }^{24}$ The mean ICS dose in the SMART group was expressed as the mean dose over all days recorded in the diaries including both maintenance and as-needed inhalations. For the UC group, the ICS dose was the prescribed dose. All different types of inhaler devices were allowed in the UC group. Data were analysed by ANOVA using an additive model with treatment as fixed factor.

The number of mild asthma exacerbation days was expressed as a percentage of the number of diary dates and compared within and between the treatment groups using a Poisson regression model. Confidence limits and $p$ values were adjusted for over dispersion. Adverse event data were analysed by descriptive statistics.

The power calculation was based on $\mathrm{PD}_{20}$-histamine and an ANOVA of the change in log ( $\mathrm{PD}_{20}$-histamine). Based on other studies, the standard deviation for ${ }^{2} \log \left(\mathrm{PD}_{20}\right.$-histamine) was expected to be 1.7. ${ }^{25}$ Under this assumption, an ANOVA with a two-sided alternative hypothesis and a significance level of $5 \%$ can detect a difference of one with $80 \%$ power, given that the study includes 50 patients per group. A difference of 1 in $\log \left(\mathrm{PD}_{20}\right.$-histamine) is equal to a difference of one doubling histamine dose.

\section{Results}

The enrolment of study subjects is summarised in Figure 2. Forty adverse events occurred in the SMART group and 42 occurred in the UC group. There were three serious adverse events, one in the SMART group (pulmonary embolism) and two in the UC group (gastritis and intervertebral disc protrusion). Four patients in the

Figure 2. Enrolment of patients and completion of the study

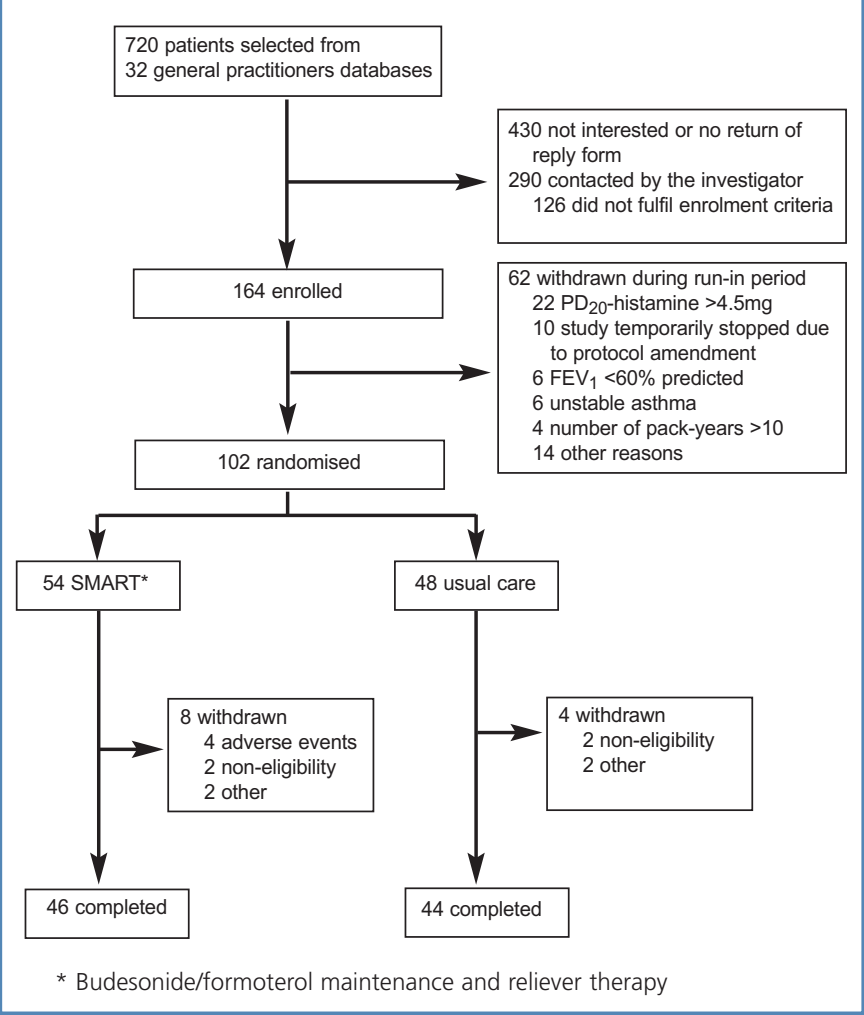


Table 1. Baseline clinical characteristics.

\begin{tabular}{|c|c|c|c|c|}
\hline Variable & & $\mathrm{SMART}^{*}(\mathrm{n}=54)$ & Usual Care $(n=48)$ & Total $(n=102)$ \\
\hline Age (years) & Mean (SD) & $44.7(13.2)$ & $40.6(12.0)$ & $42.8(12.7)$ \\
\hline Male, n (\%) & & $22(41)$ & $17(35)$ & $39(38)$ \\
\hline $\mathrm{FEV}_{1}, \%$ predicted & Mean (SD) & $96.0(16.0)$ & $101.5(17.5)$ & $98.6(16.9)$ \\
\hline $\mathrm{FEV}_{1}$ reversibility, ${ }^{+} \%$ & Mean (SD) & $7.0(5.3)$ & $6.4(4.5)$ & $6.7(4.9)$ \\
\hline $\mathrm{PD}_{20}$-histamine $(\mathrm{mg})$ & $\begin{array}{l}\text { Geometric mean } \\
\text { Range }\end{array}$ & $\begin{array}{l}0.31 \\
0.01-3.68\end{array}$ & $\begin{array}{l}0.49 \\
0.01-4.22\end{array}$ & $\begin{array}{l}0.39 \\
0.01-4.22 \\
\end{array}$ \\
\hline ICS dose ( $\mu \mathrm{g} /$ day) & Mean (SD) & $566(304)$ & $506(226)$ & $538(269)$ \\
\hline ICS dose ( $\mu \mathrm{g}$ BDP equivalents/day) & Mean (SD) & $851(484)$ & 757 (399) & $770(332)$ \\
\hline Smoking history, $\mathrm{n}(\%)^{5}$ & $\begin{array}{l}\text { Never smoker } \\
\text { Ex-smoker } \\
\text { Current smoker }\end{array}$ & $\begin{array}{l}35(65) \\
14(26) \\
5(9)\end{array}$ & $\begin{array}{l}20(42) \\
19(40) \\
9(18)\end{array}$ & $\begin{array}{l}55(54) \\
33(32) \\
14(14)\end{array}$ \\
\hline Mean daily asthma control mea & & & & \\
\hline Reliever use (inhalations/day) & Mean (SD) & $0.6(1.3)$ & $0.4(0.7)$ & $0.5(1.1)$ \\
\hline Symptom score, night (scale 0-3) & Mean (SD) & $0.2(0.3)$ & $0.3(0.4)$ & $0.2(0.4)$ \\
\hline Symptom score, day (scale $0-3$ ) & Mean (SD) & $0.3(0.4)$ & $0.5(0.5)$ & $0.4(0.5)$ \\
\hline Nights with awakenings, \% & $\begin{array}{l}\text { Mean (SD) } \\
\text { Range } \\
\end{array}$ & $\begin{array}{l}3.6(12.7) \\
0.0-85.7 \\
\end{array}$ & $\begin{array}{l}4.4(12.3) \\
0.0-53.9 \\
\end{array}$ & $\begin{array}{l}4.0(12.5 \\
0.0-85.7 \\
\end{array}$ \\
\hline Asthma control days, \% & $\begin{array}{l}\text { Mean (SD) } \\
\text { Range }\end{array}$ & $\begin{array}{l}68.0(34.5) \\
0.0-100.0 \\
\end{array}$ & $\begin{array}{l}54.4(38.7) \\
0.0-100.0 \\
\end{array}$ & $\begin{array}{l}61.6(37.0) \\
0.0-100.0\end{array}$ \\
\hline ACQ score, n (\%) & $\begin{array}{l}\text { Well-controlled } \\
\text { Not well-controlled } \\
\text { Uncontrolled }\end{array}$ & $\begin{array}{l}23(43) \\
19(35) \\
12(22) \\
\end{array}$ & $\begin{array}{l}14(29) \\
20(42) \\
14(29) \\
\end{array}$ & $\begin{array}{l}27(36) \\
39(38) \\
26(26) \\
\end{array}$ \\
\hline $\begin{array}{l}\text { * Budesonide/formoterol maintenance ar } \\
\text { †The change in the } \mathrm{FEV} \mathrm{V}_{1} \text { after inhalatior } \\
\text { ҒBDP equivalents: } 1000 \mu \mathrm{g} / \text { day beclome } \\
\text { §EX-smoker: stopped smoking at least } 6 \\
\text { १Average over the last } 10 \text { days of the } \\
\text { Uncontrolled is a mean ACQ score }>1.5\end{array}$ & $\begin{array}{l}\text { urbuhaler }{ }^{\oplus} \text {. } \\
=800 \mu \mathrm{g} / \text { day budesonid } \\
\text { ment and a smoking his } \\
\text { trolled is a mean ACQ s }\end{array}$ & $\begin{array}{l}\text { g/day fluticasone prop } \\
\text { pack-years; current s } \\
\text { 75; Not well-controlle }\end{array}$ & $\begin{array}{l}\text { ate. } \\
\text { er: smoking history }<10 \\
\text { a mean ACQ score } \geq 0.7\end{array}$ & $\begin{array}{l}\text { ack-years. } \\
\text { and } \leq 1.5\end{array}$ \\
\hline $\begin{array}{l}\text { ACQ = Asthma Control Questionnaire } \\
1 \text { second; ICS = inhaled corticosteroid }(\end{array}$ & $\begin{array}{l}\text { ptom version was used, } \\
\text { by the average of all day }\end{array}$ & $\begin{array}{l}\text { from the enrolment } v \\
\text { diaries). }\end{array}$ & $\mathrm{FEV}_{1}=$ forced expirator & volume in \\
\hline
\end{tabular}

SMART group discontinued the study because of an adverse event: the abovementioned patient with a pulmonary embolism, one patient with palpitations and tremor, and two patients due to asthma deterioration. After 1 month of treatment, four patients were withdrawn because they did not fulfil eligibility criteria retrospectively. Table 1 shows the baseline characteristics of the study participants.

There was a small but clinically irrelevant improvement in $\mathrm{PD}_{20}$-histamine in both treatment groups. The ratio of $\mathrm{PD}_{20}$ histamine values at 12 months to randomisation in the SMART group was 1.05 (95\% Cl 0.70 to 1.56) compared with 1.46 ( $95 \% \mathrm{Cl} 0.95$ to 2.22 ) in the UC group. The difference between the two treatment groups was not significant (SMART/UC ratio was $0.72(95 \% \mathrm{Cl} 0.40$ to $1.29, \mathrm{p}=0.26))$.

Table 2 summarises the outcomes of primary and secondary efficacy parameters, showing a significantly larger improvement in morning and evening PEF values and a higher rating of ease of use in the SMART group than in the UC group.

The number of days with a mild asthma exacerbation was not significantly different between SMART and UC treatment, averaging 16.4 and 16.8 mild exacerbation days/year, respectively $(p=0.80)$. A total of 11 severe asthma exacerbations occurred in both treatment groups. Two patients in the SMART group experienced a total of four exacerbations, three occurring in one patient. Six patients in the UC group experienced a total of seven exacerbations. No asthma-related hospitalisations or emergency room treatments occurred in either group.

Figure 3 shows the baseline clinical characteristics of the study participants in comparison to previously published SMART studies. ${ }^{13-18}$

The mean ICS dose decreased to $326 \mu \mathrm{g} /$ day BDP equivalents with SMART and remained almost constant at $798 \mu \mathrm{g} /$ day BDP equivalents with UC during the 12-month treatment period (Figure 4). The difference between the treatment groups was highly significant $(p<0.0001)$.

\section{Discussion}

\section{Main findings}

This study in patients with mild-to-moderate asthma in primary care shows that BHR remains stable with SMART management despite a $59 \%$ reduction in the ICS dose compared with UC treatment. Furthermore, morning and evening PEF values improved and patients were more satisfied with the ease of use of the SMART concept. The two management approaches were comparable for all other efficacy parameters. 


\begin{tabular}{|c|c|c|c|c|c|c|}
\hline Variable & Baseline & $\begin{array}{l}12 \text { months } \\
\text { Treatment }\end{array}$ & Baseline & $\begin{array}{l}12 \text { months } \\
\text { Treatment }\end{array}$ & $\begin{array}{l}\text { Difference (mean) } \\
(95 \% \mathrm{Cl})\end{array}$ & $p$ value \\
\hline Morning PEF, L/min & 441 & 458 & 449 & 447 & 23.1 (11.0 to 35.2) & 0.0003 \\
\hline Evening PEF, L/min & 450 & 460 & 456 & 453 & 16.5 (5.0 to 28.0$)$ & 0.005 \\
\hline Asthma control days, \% & 68 & 62 & 54 & 59 & $-1.04(10.5$ to 8.4$)$ & 0.83 \\
\hline Mean ACQ score & 0.80 & 0.82 & 0.93 & 0.97 & $-0.06(-0.3$ to 0.2$)$ & 0.67 \\
\hline Mean SATQ score & 5.61 & 5.83 & 5.44 & 5.55 & $0.14(-0.1$ to 0.4$)$ & 0.27 \\
\hline
\end{tabular}

Figure 3. Comparison of clinical characteristics of the current study with other SMART studies at baseline
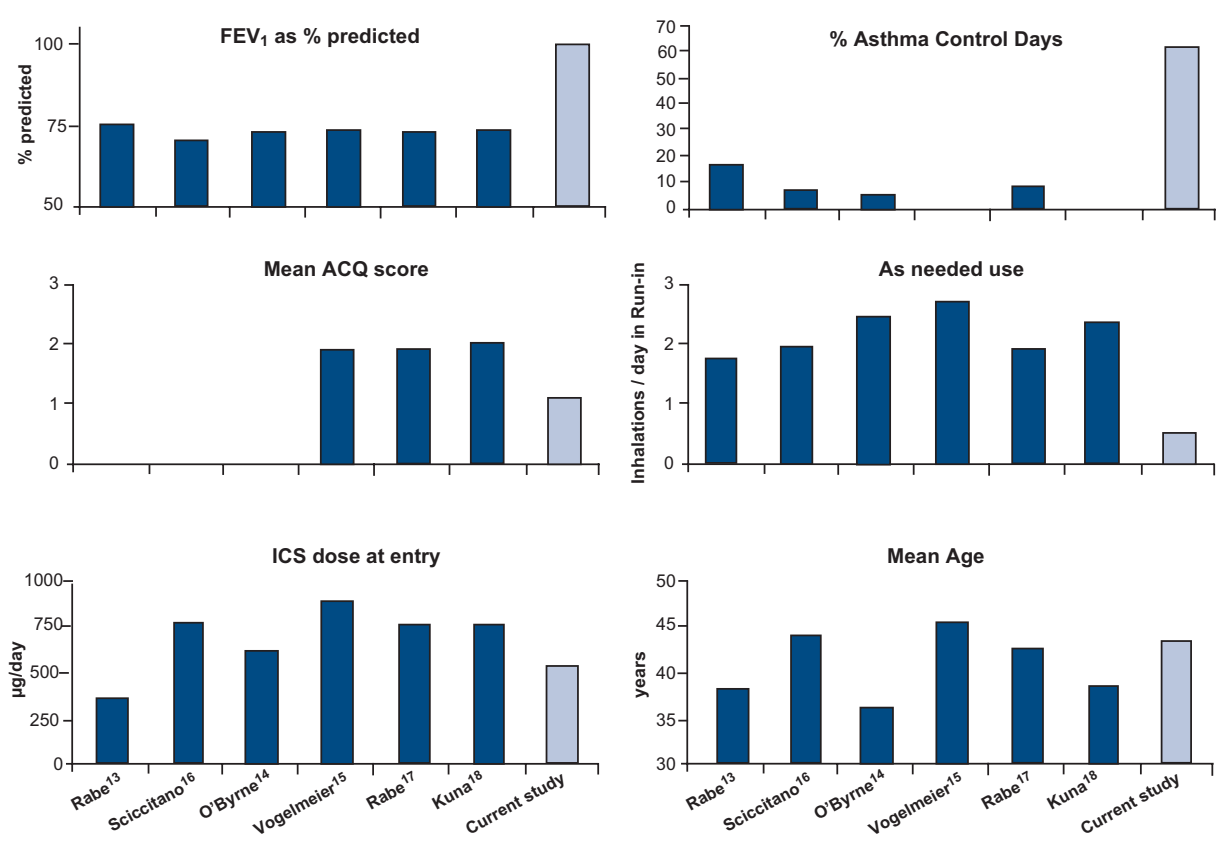

Baseline characteristics differ substantially between the patients in this primary care study and previous SMART studies ${ }^{13-}$ ${ }^{18}$ which selected outpatients from secondary care patient record files (see Figure 3). Our patients had much better FEV 1 values and ACQ scores, needed fewer inhalations of rescue medication, had more days with asthma control, and generally used a lower ICS dose at entry. Although our primary care population had milder disease in virtually every aspect of clinical characterisation, SMART treatment was beneficial in this group as well. Moreover, unlike earlier studies, there was no requirement at recruitment for symptoms/poor control so there was less potential for

regression to the mean and the use of UC as a control was easier to justify. In addition to the clinical efficacy of SMART, ratings on the domain 'ease of use' of the questionnaire on treatment satisfaction (SATQ) were significantly higher in the SMART group. This indicates that the use of one inhaler for both maintenance treatment and symptom relief was well accepted by the patients.

Despite a lower dose of ICS, the frequency of severe asthma exacerbations in the SMART group was low. The occurrence of severe exacerbations was too infrequent in both treatment groups to analyse statistically. This is an important finding 


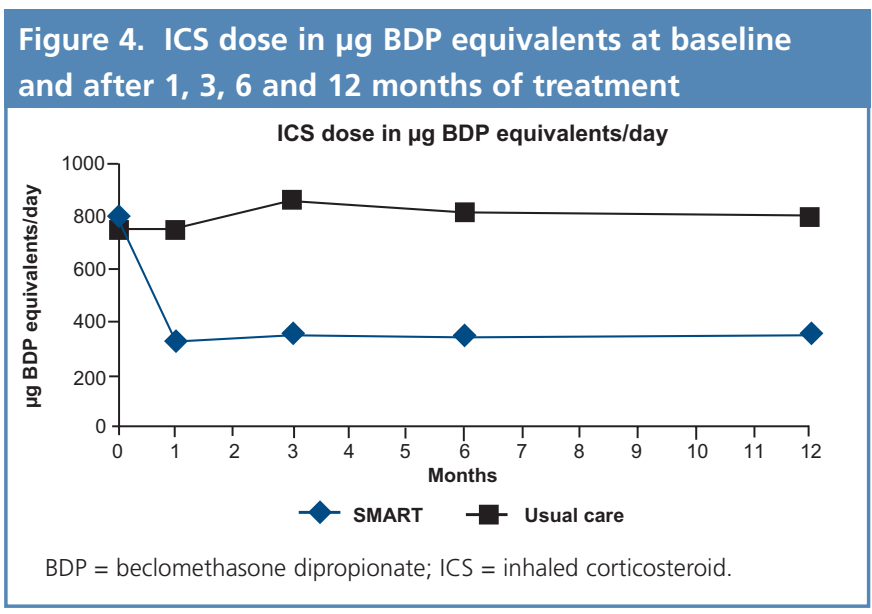

because severe exacerbations have been related to excess lung function decline in asthma, hence worse disease prognosis. ${ }^{26}$ One patient in the SMART group was responsible for three of the total number of four exacerbations. This patient did not take extra inhalations for relief, although symptom scores and PEF values in his diary clearly indicated that an exacerbation was imminent.

\section{Limitations of this study}

There are some limitations to our study. It was based on BHR resulting in relatively low numbers of patients. The effects on BHR were observed during 1-year follow-up and might have been larger after a longer duration of follow-up. Indeed, earlier studies investigating the effects of ICS on BHR for more than 1 year showed larger differences in $\mathrm{PC}_{20}$ values. However, the differences were already significant with 1 year of follow-up..$^{27,28}$ Nevertheless, we cannot fully exclude the possibility that longer treatment with SMART would have led to further differences. Patients starting with SMART had somewhat more severe asthma based on reliever use and hyperresponsiveness, although the difference was not significant. If they indeed did have somewhat more severe asthma, this might have affected the study outcome, particularly in this group. However, our results showed similar clinical outcomes with a lower cumulative ICS dose in the SMART group after 12 months of treatment. Finally, this was an open study which might affect the results, but this was necessary in order to compare the two arms of the study in a real-life situation of care in general practice.

Interpretation of findings in relation to previously published work

BHR is a risk factor for the development of asthma and impaired lung function later in life. ${ }^{29-31}$ More severe BHR predicts asthma progression, a feature generally but not invariably associated with airway wall inflammation and remodelling. ${ }^{32}$ ICS have a beneficial effect on BHR given their anti-inflammatory characteristics, with most studies showing an improvement of up to twofold. ${ }^{33,34}$ It is therefore surprising that the $\mathrm{PD}_{20}$-histamine remained stable with SMART treatment while the dose of ICS was reduced by $59 \%$. Doctors may have concerns about ICS reduction during SMART treatment and question whether this would lead to lower suppression of airway inflammation. Our data show that BHR is not worse with SMART treatment. Additionally, a Canadian study in patients with mild-to-severe asthma showed that SMART treatment had similar effects on the control of eosinophilic airway inflammation with a $26 \%$ lower overall ICS dose compared with best clinical practice treatment. ${ }^{35}$ These findings may result from enhancement of the antiinflammatory effects of ICS by simultaneously administering LABA via the same inhaler. ${ }^{12,36}$ Alternatively, since small flare-ups of inflammation may be immediately suppressed with SMART treatment but not with UC, SMART may have prevented deterioration of BHR.

Both cumulative exposure to ICS and total daily ICS dose correlate significantly with the risk of experiencing local and systemic side effects of ICS. ${ }^{37}$ Doctors should therefore strive to treat asthma patients with the lowest ICS dose possible without losing effectiveness. Our study shows that SMART treatment in a primary care setting is indeed able to do this. Papi et al. ${ }^{38}$ showed in their study in patients with mild asthma that a strictly symptom-driven use of the combination inhaler beclomethasone/salbutamol was as effective as maintenance therapy with beclomethasone alone with respect to improvements in lung function and exacerbation rates, despite a lower cumulative dose of ICS in the former group.

\section{Conclusions}

In summary, we conclude that budesonide/formoterol maintenance and reliever therapy appears to be a well-tolerated and beneficial concept for the management of patients with mild-to-moderate asthma in primary care. It reduces the dose of inhaled corticosteroids needed and can be considered as a good alternative for guideline-based treatment. Our data thus provides supportive evidence to apply SMART strategies in primary care as suggested in the recently revised GINA guidelines. ${ }^{39}$

\section{Handling editor Mike Thomas \\ Statistical review Gopal Netuveli}

Trial registration This trial is registered at: http://www.clinicaltrials.gov, identifier: NCT00235911.

Conflicts of interest RAR has received a research grant from AstraZeneca (AZ); and speaking fees, consulting fees, and reimbursement for attending conferences from AZ, GlaxoSmithKline (GSK), Boehringer, and MSD. DP has received a research grant from $A Z$; speaking fees, consulting fees, and reimbursement for attending conferences from AZ, GSK, MSD, Novartis, and Nycomed; funding for research from AZ, GSK, and Nycomed; travel to the ERS or ATS partially funded by AZ, GSK, Chiesi, and Nycomed; and she has been consultant to AZ, Boehringer Ingelheim, Chiesi, GSK, Nycomed, and TEVA. TvdM has received research grants from AZ, Nicomed, and MSD; speaking fees, consulting fees, and reimbursement for attending conferences from $A Z$ and GSK; and has been consultant to $A Z, M S D$, Nicomed, and Novartis.

Contributorship The authors wrote the manuscript. Employees of the sponsor performed data monitoring. Data analysis was performed by employees of the sponsor and the authors. The corresponding author had access to the full clinical trial database and all authors had free access to the clinical study report and the results of the statistical analyses. Employees of the sponsor reviewed drafts of the manuscript and made editing suggestions. All authors made the final decisions on 
all aspects of the manuscript.

Funding This study was supported by an unrestricted educational grant by AstraZeneca BV, The Netherlands. The sponsors were involved in the study design and interpretation of the data, always in conjunction with the study investigators.

\section{References}

1. Global Initiative for Asthma (GINA). Global strategy for Asthma Management and Prevention (updated 2004). NIH Publication No. 02-3659. Bethesda, MD: National Institutes of Health, 2004

2. Rabe KF, Vermeire PA, Soriano JB, Maier WC. Clinical management of asthma in 1999: the Asthma Insights and Reality in Europe (AIRE) Study. Eur Respir J 2000;16:802-7. http://dx.doi.org/10.1183/09031936.00.16580200

3. Partridge MR, van der Molen T, Myrseth SE, Busse WW. Attitudes and actions of patients with asthma on regular maintenance therapy: the INSPIRE study. BMC Pulm Med 2006;6:13. http://dx.doi.org/10.1186/1471-2466-6-13

4. Pauwels RA, Lofdahl CG, Postma DS, et al. Effect of inhaled formoterol and budesonide on exacerbations of asthma. N Engl J Med 1997;337:1412-18. http://dx.doi.org/10.1056/NEJM199711133372001

5. O'Byrne PM, Barnes PJ, Rodriguez Roisin R, et al. Low dose inhaled budesonide and formoterol in mild persistent asthma: the OPTIMA randomized trial. Am J Respir Crit Care Med 2001;164:1392-7.

6. Shrewsbury S, Pyke S, Britton M. Meta-analysis of increased dose of inhaled steroid or addition of salmeterol in symptomatic asthma (MIASMA). BMJ 2000;320:136873. http://dx.doi.org/10.1136/bmj.320.7246.1368

7. Kankaanranta $\mathrm{H}$, Lahdensuo A, Moilanen E, Barnes PJ. Add-on therapy options in asthma not adequately controlled by inhaled corticosteroids: a comprehensive review. Respir Res 2004;5:17-42. http://dx.doi.org/ 10.1186/1465-9921-5-17

8. Seberová E, Andersson A. Oxis (formoterol given by Turbuhaler) showed as rapid an onset of action as salbutamol given by a pMDI. Respir Med 2000;94:607-11. http://dx.doi.org/10.1053/rmed.2000.0788

9. Pauwels RA, Sears MR, Campbell M, et al, for the RELIEF Study Investigators. Formoterol as relief medication in asthma: a worldwide safety an effectiveness trial. Eur Respir J 2003;22:787-94. http://dx.doi.org/10.1183/09031936.03.00055803

10. Tattersfield AE, Löfdahl CG, Postma DS, et al. Comparison of formoterol and terbutaline for as-needed treatment of asthma: a randomised trial. Lancet 2001;357:257-61. http://dx.doi.org/10.1016/S0140-6736(00)03611-4

11. Molen van der T, Postma DS, Turner MO, et al. Effects of the long acting $\beta 2$-agonist formoterol on asthma control in asthmatic patients using inhaled corticosteroids. Thorax 1997;6:535-9

12. Barnes PJ. Scientific rationale for using a single inhaler for asthma control. Eur Respir J 2007;29:1-9. http://dx.doi.org/10.1183/09031936.00080306

13. Rabe KF, Pizzichini E, Ställberg B, et al. Budesonide/formoterol in a single inhaler for maintenance and relief in mild-to-moderate asthma. Chest 2006;129:246-56. http://dx.doi.org/10.1378/chest.129.2.246

14. O'Byrne PM, Bisgaard H, Godard P, et al. Budesonide/formoterol combination therapy as both maintenance and reliever medication in asthma. Am J Respir Crit Care Med 2005;171:129-36. http://dx.doi.org/10.1164/rccm.200407-8840C

15. Vogelmeier C, D'Urzo A, Pauwels R, et al. Budesonide/formoterol maintenance and reliever therapy: an effective asthma treatment option? Eur Respir J 2005;26:81928. http://dx.doi.org/10.1183/09031936.05.00028305

16. Scicchitano $R$, Aalbers $R$, Ukena $D$, et al. Efficacy and safety of budesonide/formoterol single inhaler therapy versus a higher dose of budesonide in moderate to severe asthma. Curr Med Res Opin 2004;20:1403-18. http://dx.doi.org/10.1185/030079904X2051

17. Rabe KF, Atienza T, Magyar P, Larsson P, Jorup C, Lallo G. Effect of budesonide in combination with formoterol for reliever therapy in asthma exacerbations: a randomised controlled, double-blind study. Lancet 2006;368:744-53. http://dx.doi.org/10.1016/S0140-6736(06)69284-2

18. Kuna P, Peters MJ, Manjra Al, et al. Effect of budesonide/formoterol maintenance and reliever therapy on asthma exacerbations. Int J Clin Pract 2007;61:725-36. http://dx.doi.org/10.1111/j.1742-1241.2007.01338.x

19. Dusser D, Montani D, Chanez $P$, et al. Mild asthma: an expert review on epidemiology, clinical characteristics and treatment recommendations. Allergy 2007;62:591-604. http://dx.doi.org/10.1111/j.1398-9995.2007.01394.x

20. Juniper EF, O'Byrne PM, Roberts JN. Measuring asthma control in group studies: do we need airway calibre and rescue 32 -agonist use? Respir Med 2001;95:319-23. http://dx.doi.org/10.1053/rmed.2001.1034

21. Juniper EF, O'Byrne PM, Guyatt GH, Ferrie PJ, King DR. Development and validation of a questionnaire to measure asthma control. Eur Respir J 1999;14:902-07. http://dx.doi.org/10.1034/j.1399-3003.1999.14d29.x

22. Campbell JL, Kiebert GM, Partidge MR. Development of the Satisfaction with inhaled Asthma Treatment Questionnaire. Eur Respir J 2003;22:127-34. http://dx.doi.org/10.1183/09031936.03.00097503

23. Sterk PF, Fabbri LM, Quanjer PH, et al. Airway responsiveness: standardized challenge testing with pharmacological, physical and sensitizing stimuli in adults. Report Working Party, Standardization of Lung Function Tests, European Community for Steel and Coal. Official statement of the European Respiratory Society. Eur Respir J 1993;6(Suppl):53-83.

24. Mollmann $H$, Wagner $M$, Krishnaswami $S$, et al. Single-dose and steady-state pharmacokinetic and pharmacodynamic evaluation of therapeutically clinically equivalent doses of inhaled fluticasone propionate and budesonide, given as Diskus or Turbohaler dry-powder inhalers to healthy subjects. J Clin Pharmacol 2001;41:1329-38. http://dx.doi.org/10.1177/00912700122012913

25. Osterman K, Carlholm M, Ekelund J, et al. Effect of 1 year daily treatment with 400 Ìg budesonide (Pulmicort ${ }^{\oplus}$ Turbuhaler $^{\circledast}$ ) in newly diagnosed asthmatics. Eur Respir $J$ 1997;10:2210-15. http://dx.doi.org/10.1183/ 09031936.97.10102210

26. Bai TR, Vonk JM, Postma DS, Boezen HM. Severe exacerbations predict excess lung function decline in asthma. Eur Respir J 2007;30:452-6. http://dx.doi.org/10.1183/09031936.00165106

27. Kerstjens HA, Brand PL, Hughes MD, et al. A comparison of bronchodilator therapy with or without inhaled corticosteroid therapy for obstructive airways disease. Dutch Chronic Non-Specific Lung Disease Study Group. N Eng J Med 1992;327:1413-19. http://dx.doi.org/10.1056/NEJM199211123272003

28. Haahtela $T$, Jarvinen $M$, Kava $T$, et al. Effects of reducing or discontinuing inhaled budesonide in patients with mild asthma. N Engl J Med 1994;331:700-5. http://dx.doi.org/10.1056/NEJM199409153311103

29. Hargrave FE, Ryan G, Thomson NC, et al. Bronchial responsiveness to histamine or methacholine in asthma: measurement and clinical significance. J Allergy Clin Immunol 1981;68:347-55. http://dx.doi.org/10.1016/0091-6749(81)90132-9

30. Jansen DF, Rijcken B, Schouten JP, et al. The relationship of skin test positivity, high serum total IgE levels, and peripheral blood eosinophilia to symptomatic and asymptomatic airway hyperresponsiveness. Am J Respir Crit Care Med 1999;159:924-31.

31. Xu X, Rijcken B, Schouten JP, Weiss ST. Airways responsiveness and development and remission of chronic respiratory symptoms in adults. Lancet 1997;350:1431-4. http://dx.doi.org/10.1016/S0140-6736(97)10041-1

32. James $\mathrm{AL}$, Wenzel $\mathrm{S}$. Clinical relevance of airway remodelling in airway diseases. Eur Respir J 2007;30:134-55. http://dx.doi.org/10.1183/09031936.00146905

33. Kraan J, Koëter GH, Mark van der ThW, Sluiter HJ, Vries de K. Changes in bronchial hyperreactivity induced by 4 weeks of treatment with antiasthmatic drugs in patients with allergic asthma: a comparison between budesonide and terbutaline. J Allergy Clin Immunol 1985;76:628-36. http://dx.doi.org/ 10.1016/0091-6749(85)90786-9

34. Kraan J, Koëter GH, Mark van der TW, et al. Dosage and time effects of inhaled budesonide on bronchial hyperreactivity. Am Rev Respir Dis 1988;137:44-8. http://dx.doi.org/10.1164/ajrccm/137.1.44

35. Sears MR, Boulet LP, Laviolette $M$, et al. Budesonide/formoterol maintenance and reliever therapy: impact on airway inflammation in asthma. Eur Respir J 2008;31:982-9. http://dx.doi.org/10.1183/09031936.00104007

36. Kauer M, Chivers JE, Giembycz MA, Newton R. Long-acting $\beta 2$-adrenoceptor agonists synergistically enhance glucocorticoid-dependent transcription in human airway epithelial and smooth muscle cells. Mol Pharmacol 2008;73:203-14. http://dx.doi.org/10.1124/mol.107.040121

37. Foster JM, Aucott L, van der Werf RH, et al. Higher patient perceived side effects related to higher daily doses of inhaled corticosteroids in the community: a crosssectional analysis. Respir Med 2006;100:1318-36. http://dx.doi.org/10.1016/j.rmed.2005.11.029

38. Papi A, Canonica G, Mestrelli P, et al. Rescue use of beclomethasone and albuterol in a single inhaler for mild asthma. N Engl J Med 2007;356:2040-52. http://dx.doi.org/10.1056/NEJMoa063861

39. Global Initiative for Asthma (GINA). Global Strategy for Asthma Management and Prevention, revised 2006. www.ginasthma.com 
Appendix 1: Enrolment, exclusion and randomisation criteria

\section{enrolment criteria}

Written informed consent

Outpatients selected from GP practices

Doctors diagnosis mild-moderate asthma

Age $\geq 18$ years of either sex

FEV $1 \geq 60 \%$ of predicted normal

Daily use of inhaled corticosteroids during the last months prior to enrolment

\section{exclusion criteria}

Regular need of $>4$ inhalation of rescue medication/day

Intermittent or severe asthma

Respiratory infection affecting the patient's asthma within 1 month prior to enrolment

Intake or oral, rectal or parenteral GCS within 1 month prior to enrolment

Smoking history $\geq 10$ pack-years

Use of any $\beta$-blocking agent, including eye drops

Significant co morbidity putting the patient at risk or influencing the study results

Pregnancy, breast-feeding or planed pregnancy

Planned hospitalisation during the study

Previous randomisation in this study

Participation in another clinical study within 1 month before enrolment

\section{randomisation criteria}

$P D_{20}$-histamine $\leq 4.5 \mathrm{mg}$

Correct inhalation technique

$<10$ inhalations of as-needed medication on any day during the run-in period

No asthma exacerbations during the run-in period

During the last month prior to randomisation the daily dose of ICS should be constant and:

a. $\leq 800 \mu \mathrm{g}$ budesonide/beclomethasone or $\leq 500 \mu \mathrm{g}$ fluticasone if used in combination with long-acting 32 -agonist

b. $\leq 1600 \mu \mathrm{g}$ budesonide/beclomethasone or $51000 \mu \mathrm{g}$ fluticasone if used without long-acting $\beta 2$-agonist

still be eligible in accordance with the exclusion criteria 